\title{
Eating behaviour and retro-nasal aroma release in normal-weight and overweight adults: a pilot study
}

\author{
Nicolien Zijlstra ${ }^{1,2}$, Andrea Johanna Bukman ${ }^{2}$, Monica Mars ${ }^{1,2}$, Annette Stafleu ${ }^{1,3}$, \\ Rianne M. A. J. Ruijschop ${ }^{4}$ and Cees de Graaf ${ }^{1,2 *}$ \\ ${ }^{1}$ Top Institute Food and Nutrition, PO Box 557, 6700 AN Wageningen, The Netherlands \\ ${ }^{2}$ Division of Human Nutrition, Wageningen University, PO Box 8129, 6700 EV Wageningen, The Netherlands \\ ${ }^{3}$ TNO Quality of Life, PO Box 360, 3700 AJ Zeist, The Netherlands \\ ${ }^{4}$ NIZO Food Research, PO Box 20, 6710 BA Ede, The Netherlands
}

(Received 7 May 2010 - Revised 25 November 2010-Accepted 7 January 2011 - First published online 9 March 2011)

\section{Abstract}

Eating rate and bite size are important factors affecting food intake, and we hypothesise the underlying role of oral sensory exposure in this. However, the latter currently lacks objective measuring parameters, but an interesting measure could be the extent of in vivo retronasal aroma release. Second, the literature is ambiguous about overweight subjects differing from normal-weight subjects in eating behaviour. Consequently, we investigated: (1) whether eating behaviour (food intake, eating rate, bite size, number of bites and meal duration) relates to weight status and (2) whether the extent of retro-nasal aroma release relates to eating behaviour and weight status. A matched group (sex, age and dietary restraint) of twenty-seven normal-weight (BMI 21.8 (SD 1.6 ) $\mathrm{kg} / \mathrm{m}^{2}$ ) and twenty-seven overweight/obese subjects (BMI $30.5(\mathrm{SD} 5.8) \mathrm{kg} / \mathrm{m}^{2}$ ) consumed a spiced rice meal and apple pie yogurt on separate test days. The extent of retro-nasal aroma release was measured on a third test day. Mean bite size for spiced rice was significantly $(P=0.03)$ larger in overweight/obese $(10.3$ (SD 3.2) g) $v$. normal-weight subjects ( 8.7 (SD 2.1) g). There were no other significant differences in eating behaviour or retro-nasal aroma release between the groups. Eating behaviours were not correlated with BMI or retro-nasal aroma release. Subjects showed consistent eating behaviour for both test products. Eating behaviour might be a characteristic of an individual but not by definition a characteristic for a group of people based on their weight. Given the large sample sizes, necessary according to a posteriori sample size calculations, one needs to consider the relevance of finding a statistically significant difference in eating behaviour between the weight groups in a laboratory setting.

Key words: Eating behaviour: Food intake: Retro-nasal aroma release: Individuals: BMI

Given the growing rate of obesity ${ }^{(1)}$, we need to know more about the factors influencing food intake. The rate of eating and bite size are important factors shown to affect intake $^{(2-6)}$. Food characteristics such as food texture have an effect on these factors. A recent study of Viskaal-van Dongen et $a l^{(7)}$ has shown that eating rates differed enormously between a number of frequently consumed foods. In our previous studies, we have shown that a liquid product was eaten faster and with larger bite sizes than the same product in a semi-solid form ${ }^{(5,8)}$. Next to food characteristics, individual aspects determine eating behaviour. In a previous study, we have observed that subjects who consumed one product faster also consumed the other products faster ${ }^{(9)}$. Spiegel et $a l .{ }^{(10)}$ observed that subjects who ate the most, paused the most or chewed the fastest in one condition also did this in the other conditions. Westerterp et al. ${ }^{(11)}$ also showed consistency in individual eating behaviour for chewing time per bite and bite interval.

Based on our previous studies ${ }^{(5,6)}$, we expect that oral sensory exposure is an important underlying factor involved in the relationship of eating rate and bite size to food intake. Eating slowly and taking more time to process the food in the mouth results in longer oral exposure time. This longer oral exposure time may lead to earlier sensory satiation and a lower ad libitum food intake. Additionally, eating with small bite sizes may lead to relatively more oral sensory exposure to a product. Currently, there is no direct objective measure for oral sensory exposure available, but a novel interesting measure is the extent of in vivo retro-nasal aroma release $\mathrm{e}^{(12,13)}$.

Abbreviations: AUC, area under the curve; VAS, visual analogue scale.

*Corresponding author: C. de Graaf, fax +31 317 483342, email kees.degraaf@wur.nl 
Retro-nasal aroma release is an important aspect in the sensory perception of a product. The transfer of aroma via the retro-nasal route is also related to the texture and the volume (i.e. bite size) of food in the mouth ${ }^{(14)}$. Additionally, different eating styles related to chewing force, chewing rate and number of chews have been shown to result in differences in aroma release measurements ${ }^{(15)}$. Furthermore, in a recent study of Ruijschop et $a l .{ }^{(16)}$, the extent of retronasal aroma release appeared to be subject specific, and an inverse trend was observed between aroma release and ad libitum food intake $(P=0.07)$. Together, the aforementioned information indicates that in vivo retro-nasal aroma release might be a possible marker for oral sensory exposure. Although this technique measures aroma release and not all of oral sensory exposure, it is a novel and interesting measure to investigate.

Although data are ambiguous, studies have indicated that overweight and/or obese subjects may have a different eating behaviour compared with normal-weight subjects ${ }^{(17-20)}$. These groups might thus potentially also differ in the extent of oral sensory exposure and in the extent of in vivo retro-nasal aroma release.

Consequently, the aims of the present study were to investigate (1) whether eating behaviour (food intake, eating rate, bite size, number of bites and meal duration) relates to weight status and (2) whether the extent of retro-nasal aroma release relates to eating behaviour or weight status. To study these aims, eating behaviour was investigated in a controlled manner of observation (including weighing scale and video observations) but in an uncontrolled manner of eating (without giving instructions on eating rate and bite size), and the extent of in vivo retro-nasal aroma release was measured on a separate day. As far as we know, we are one of the first to investigate the extent of retro-nasal aroma release in a large group of subjects with different BMI and relate this directly to eating behaviour such as ad libitum intake and eating rate.

\section{Subjects and methods}

\section{Subjects}

Subjects were recruited in the surroundings of Ede and Wageningen (The Netherlands) via flyers, advertisements in local papers, posters and emails to persons in a database of volunteers willing to participate in studies of Wageningen University. Furthermore, some participants were recruited via a recruitment agency who emailed potential overweight and obese subjects in their database. Subjects had to be healthy, 18-55 years old, normal weight (BMI $18.5-25 \cdot 0 \mathrm{~kg} / \mathrm{m}^{2}$ ) or overweight/obese (BMI $>25.0 \mathrm{~kg} / \mathrm{m}^{2}$ ), and they had to like the test products (scoring liking $\geq 5$ on a nine-point scale with a description of the test products). Exclusion criteria were as follows: lack of appetite for any reason; following an energy-restricted diet during the last 2 months or planning to start an energy-restricted diet during the time of the study; change in body weight $>5 \mathrm{~kg}$ during the last 2 months; stomach or bowel diseases, diabetes, thyroid disease or any other endocrine disorders; having difficulties with eating or swallowing; hypersensitivity for the test products. Our aim was to include average consumers; no smell or taste tests had been performed by the subjects.

Potential subjects were invited for a screening/training visit to Wageningen University, during which body weight and height were measured. Furthermore, subjects practised with the computer program, which was used for satiety and sensory ratings on visual analogue scales (VAS) and for a computerised food preference questionnaire. No food was provided during the training session.

Subjects were not aware that the aim of the study was to measure eating behaviour but were informed that the study was performed to measure the pleasantness of different products and to investigate whether this correlates to the extent of retro-nasal aroma release. The present study was conducted according to the guidelines laid down in the Declaration of Helsinki, and all procedures involving human subjects were approved by the Medical Ethical Committee of Wageningen University. Written informed consent was obtained from all subjects.

Overweight/obese subjects were individually matched with normal-weight subjects, based on sex, age and restraint eating score (Dutch Eating Behaviour Questionnaire) ${ }^{(21)}$. The data of fifty-four subjects were included in the data analysis of eating behaviour, which included twenty-seven overweight/obese subjects (six men and twenty-one women, mean BMI 30.5 (SD 5.7$) \mathrm{kg} / \mathrm{m}^{2}$, mean age 36 (SD 14) years and mean restraint score 2.9 (SD 0.7)) matched with twenty-seven normal-weight subjects (six men and twenty-one women, mean BMI 21.8 (SD 1.6$) \mathrm{kg} / \mathrm{m}^{2}$, mean age 36 (SD 14) years and mean restraint score $2.9(\mathrm{SD}$ 0.8)). The overweight/obese subject group will hereafter be referred to as the 'overweight group', and data of both the overweight and obese subjects are included in the results of this group. Retro-nasal aroma release data of twenty-four matched pairs ( $n$ 48) were available for data analysis.

\section{Experimental design}

The study had a randomised cross-over design in which all subjects came twice to Wageningen University (Wageningen, The Netherlands) for a sensory test session. Subjects participated in a third session at NIZO Food Research (Ede, The Netherlands) during which the extent of in vivo retro-nasal aroma release was measured.

\section{Test products}

A simple spiced rice (Dutch: nasi) was chosen as a neutrally liked meal product and a sweet, creamy apple pie yogurt with currants as a highly liked product. Data of the sensory sessions showed that the mean liking was 67 (SD 16) for the rice, and the mean liking was 83 (SD 13) for the yogurt (100 units VAS, no differences between the weight groups, $P<0.001$ between the products). Other sensory ratings (100unit VAS) were as follows: rice, mean saltiness 49 (SD 20) 
and spiciness 28 (SD 21); yogurt, mean sweetness 69 (SD 16) and creaminess 76 (SD 13).

At $1 \mathrm{~h}$ before each sensory test session, the spiced rice was prepared in a standardised manner with white rice (AH private label; Albert Heijn, Zaandam, The Netherlands) and nasi flavourings (Knorr; Unilever, Rotterdam, The Netherlands). The prepared product was stored in a bain-marie at $80^{\circ} \mathrm{C}$. The serving temperature was measured between 67 and $71^{\circ} \mathrm{C}$. The apple pie yogurt was a commercially available product (Mona; FrieslandCampina Consumer Products Europe, Amersfoort, The Netherlands). The yogurt was stored in a refrigerator between 3 and $5^{\circ} \mathrm{C}$ and removed at a standardised time before the test session. The serving temperature was measured between 8.5 and $10^{\circ} \mathrm{C}$.

For the retro-nasal aroma release session, the spiced rice was prepared beforehand in the same manner as described earlier and afterwards deep-frozen. Before the test session, the rice was defrosted, heated in a microwave and kept warm in a water-bath of $37^{\circ} \mathrm{C}$ before serving. The apple pie yogurt was stored in a refrigerator at $4^{\circ} \mathrm{C}$ and removed at a standardised time before the start of the measurements.

Macronutrient content was determined by chemical analysis, protein by the Kjeldahl method ${ }^{(22)}$, fat by the acid hydrolysis method ${ }^{(23)}$, fibre by the Prosky method ${ }^{(24)}$; subsequently, carbohydrate was calculated by subtracting moisture, ash, fibre, protein and fat from the total weight. Energy content was calculated from the macronutrient composition by using the following energy conversion factors: protein $16.7 \mathrm{~kJ} / \mathrm{g}$; fat $37.7 \mathrm{~kJ} / \mathrm{g}$; carbohydrate $15.7 \mathrm{~kJ} / \mathrm{g}$. Per $100 \mathrm{~g}$, the spiced rice contained $563 \mathrm{~kJ}$ ( $134 \mathrm{kcal}), 3 \cdot 2 \mathrm{~g}$ protein, $27.3 \mathrm{~g}$ carbohydrates, $2.2 \mathrm{~g}$ fat and $1.6 \mathrm{~g}$ fibre. Per $100 \mathrm{~g}$, the apple pie yogurt contained $522 \mathrm{~kJ}(125 \mathrm{kcal}), 2.3 \mathrm{~g}$ protein, $16.4 \mathrm{~g}$ carbohydrates, $6.0 \mathrm{~g}$ fat and $0.3 \mathrm{~g}$ fibre.

\section{Procedure sensory test sessions}

The two sessions at Wageningen University were separated by at least $1 \mathrm{~d}$ and were held in the sensory cabins around lunchtime, starting at $11.30,12.30$ or 13.30 hours. For every subject, the second test session started at the same time as the first test session. The order of the test products was randomly allocated to the subjects. However, the rice and yogurt were never given to different subjects in the same session, since the smell of the rice could influence the eating behaviour of the apple pie yogurt.

At the beginning of the session, subjects rated hunger, fullness, desire to eat, appetite for something sweet, appetite for something savoury, prospective consumption and thirst on 100-unit VAS on a computer screen. Scales were anchored from 'not at all/very little' to 'very much'.

When finishing the ratings, explicit and implicit aspects of food choice were assessed by means of a computerised food preference questionnaire (paradigm of Finlayson et $a{ }^{(25,26)}$, data not shown in the present study). Next, subjects received a small amount of the test product (on average 31 (SD 4) $\mathrm{g}$ spiced rice or 47 (SD 4) g apple pie yogurt) to rate liking and other sensory attributes of the test products on 100-unit VAS. After that, subjects received a large bowl of the test product and were instructed to eat as much of the products as they wanted until they were pleasantly satiated. In order to try to keep any visual or weight cues from the subjects and to stimulate ad libitum intake, a surplus of the test product was served; on average 901 (SD 7) g spiced rice and 1301 (SD 1) g apple pie yogurt. The offered amount in weight was different between the products because of differences in energy density, but visually the bowls were filled with approximately the same volume. After ad libitum intake, subjects had to rate their degree of hunger and satiety again by the same questions as in the beginning of the session, received a small amount of the test product (on average 32 (SD 4) g spiced rice or 47 (SD 3) g apple pie yogurt), had to rate liking and sensory attributes again, and the food preference questionnaire was rerun.

To prevent subjects leaving early or stopping with eating because of other reasons than being satiated, they were instructed to stay at least $45 \mathrm{~min}$ in the sensory cabins. Additionally, we wanted to prevent subjects distracting each other when finished, and this time period allowed everyone to finish eating at their own pace. Subjects were provided reading material when finished.

\section{Measurements of eating behaviour}

Food intake was measured via hidden electronic scales (KERN 440; ATP-Messtechnik, Ballingen, Germany) in the tables of the sensory cabins. Data were saved by specially developed software. During eating, weight of the offered test meal was registered every $0.5 \mathrm{~s}$. In addition, the product was weighed before the meal was offered and immediately after the subjects returned the bowl, which was done on a different electronic scale (model 1203-MP; Sartorius, Goettingen, Germany).

The test sessions were videotaped via a camera. The video recordings were compared with the data of the electronic scales to determine total ad libitum intake, meal duration, eating rate, number of bites and bite size in an accurate way. To reduce errors in weighing, participants were given instructions to only take food on their spoon until ready to ingest it, not to leave the spoon in the bowl during eating and to leave the spoon next to the food bowl when completing ratings or finished eating. Intake, meal duration, eating rate, number of bites and bite size were measured in the following way:

Total ad libitum intake. The difference between the weight of the product before the meal was offered and the weight after the subject returned the bowl.

Meal duration. The subject-defined eating period. In the computer program, the subjects had to press an 'I start with eating' button and an 'I am satisfied' button. The time difference between these two moments was defined as the meal duration. For seven of the 108 measurements, the actual meal duration was longer since the subjects took one or more bites before or after this time period, which was observed on the video recordings. Using these recordings, we corrected meal duration; the time between the spoon touching the food and the last chewing movements outside 
the self-defined period was added, to approach the true meal duration. For one subject, the actual meal duration was shorter since this person forgot to press the 'I am satisfied button'. Meal duration was again corrected by means of the video recordings.

Eating rate. The total ad libitum intake (in g) divided by meal duration (in min). Initial eating rate and deceleration rate were calculated from curve fitting the cumulative intake curves (see Statistical analysis).

Number of bites. The number of bites counted from the video recordings. A bite was defined as a contact with the food followed by chewing or swallowing. When subjects took two bites from one spoonful, which were both followed by a period of chewing and swallowing, this was counted as two bites.

Bite size. Total ad libitum intake divided by the number of bites.

\section{Standardisation of satiety state for the sensory test sessions}

To standardise the individual state of satiety, subjects were instructed to eat the same breakfast at home on both test days and to record their food and drink consumption in a diary. This diary was checked upon arrival at the test location, before the start of the test session. Furthermore, they were instructed not to consume anything except water after 10.00 hours and until $1 \mathrm{~h}$ after the test session. This last instruction was not controlled but was given to promote subjects consuming until satiated from the test products.

\section{Procedure and measurements of in vivo retro-nasal aroma release}

The retro-nasal aroma release session took place between 08.30 and 16.00 hours. Subjects were instructed not to consume coffee in the $2 \mathrm{~h}$ before the test session and not to use strong perfumes or deodorants on the day of the measurement. This was checked by the researchers upon arrival.

Before the in vivo retro-nasal aroma release measurements, the aroma compounds with the highest response in air released from an artificial mouth were monitored by online sampling by an atmospheric pressure chemical ionisation gas-phase analyser attached to a VG Quattro II mass spectrometer (MS-Nose; Micromass UK Limited, Manchester, $\mathrm{UK})^{(12,13,27,28)}$. Compounds were ionised by a $3.0 \mathrm{kV}$ discharge (source and probe temperature were $80^{\circ} \mathrm{C}$ ) and scanned for $m / z 50-250$. The $m / z$ values (i.e. the ion mass-to-charge ratio of a specific aroma component) with the highest response were selected (Table 1 ).

During the test session, in vivo retro-nasal aroma release was assessed in the exhaled breath of the subjects using real-time atmospheric pressure chemical ionisation-MS. Subjects consumed three consecutive spoonfuls of the test products (fixed amount, on average 12 (SD 2) g of spiced rice and 19 (SD 1) g of apple pie yogurt). During eating, subjects breathed in and out via the nose, while one nostril was placed over a small disposable plastic tube. Subjects could breathe and eat normally; no chewing/swallowing instructions were given. Aroma compounds in the air released from the exhaled breath of the subjects were monitored by online sampling of the exhaled air directly into the atmospheric pressure chemical ionisation-MS via the tube. The air was sampled $(75 \mathrm{ml} / \mathrm{min})$ through a capillary tube $(0.53 \mathrm{~mm}$ in internal diameter, heated to $\left.100^{\circ} \mathrm{C}\right)$. The compounds were monitored in selected ion mode ( $0.08 \mathrm{~s}$ dwell on each ion), in two independent sets. The cone voltage was $20 \mathrm{~V}$.

The two food products were measured separately. First, the spiced rice was measured followed by the apple pie yogurt. Subjects consumed a plain cracker and rinsed their mouths with water between the two test products. Blank experiments with water were recorded before the consumption of the test products, according to the same protocol.

Acetone, present in human breath, was measured at $m / z 59$ $(19 \mathrm{~V})$ as an indicator for the breathing pattern ${ }^{(12,29)}$. The area of the resulting breath peaks in the aroma signal was taken as a measure of in vivo retro-nasal aroma release. Since we were interested in comparative retro-nasal aroma release between subjects, expression of the extent of retro-nasal aroma release in arbitrary units was sufficient to analyse differences ${ }^{(12)}$. The following parameters were extracted from each individual retro-nasal aroma release curve:

1. $I_{\max }=$ the maximum intensity (arbitrary units)

2. $T_{\max }=$ the time at which maximum intensity occurs $(\min )$

Table 1. Test products used during the in vivo retro-nasal aroma release session, their serving and weight and with their $\mathrm{m} / \mathrm{z}$ value with the highest response in atmospheric pressure chemical ionisation mass spectrometry measurement

(Mean values and standard deviations)

\begin{tabular}{|c|c|c|c|c|c|}
\hline \multirow[b]{2}{*}{ Product } & \multirow{2}{*}{$\begin{array}{l}\text { Serving per } \\
\text { measurement }\end{array}$} & \multicolumn{2}{|c|}{$\begin{array}{c}\text { Weight per } \\
\text { serving spoon }(g)\end{array}$} & \multirow{2}{*}{$\begin{array}{l}\text { Ion mass } \\
\text { ( } m / z \text { value })\end{array}$} & \multirow{2}{*}{$\begin{array}{c}\text { Aroma } \\
\text { component }\end{array}$} \\
\hline & & Mean & SD & & \\
\hline Spiced rice & One spoonful & 2 & & $\begin{array}{l}73 \\
87\end{array}$ & $\begin{array}{l}\text { 2-Butanone } \\
\text { Diacetyl } \\
\text { Pentatone }\end{array}$ \\
\hline Apple pie yogurt & One spoonful & 19 & 1 & $\begin{array}{l}137 \\
149\end{array}$ & $\begin{array}{l}\text { Limonene } \\
\text { Terpinene } \\
\text { Cumic aldehyde }\end{array}$ \\
\hline
\end{tabular}


3. Area under the curve (AUC) $=$ the total AUC (arbitrary units $\times$ min)

The characteristic retro-nasal aroma release parameters ( $T_{\max }, I_{\max }$ and AUC) were averaged for each subject, for each product from the three consecutive bites. This procedure is allowed, since subjects are reproducible in their extent of retro-nasal aroma release during consumption of a specific food product ${ }^{(14,16)}$. Due to the lower signal-to-noise ratio for the $m / z$ values 137 (spiced rice) and 87 (apple pie yogurt) compared with the $\mathrm{m} / z$ values 149 (spiced rice) and 73 (apple pie yogurt), the background noise, as measured with the blank experiments, was subtracted from the measurements with the two test products per subject for all $\mathrm{m} / z$ values.

After consuming the test products for the retro-nasal aroma release measurements, subjects rated the intensities of smell, taste and aftertaste of the product on $100 \mathrm{~mm}$ VAS, anchored from 'not at all intense' to 'very intense' (data not shown, but no significant differences between the weight groups).

\section{Statistical analysis}

Data are presented as means and standard deviations. Statistical analyses were performed by means of the SAS statistical software package version 9.1.3 (SAS Institute, Cary, NC, USA). Significance was set at $P<0.05$, and quoted significance levels were two-sided.

Differences in liking, sensory ratings, eating behaviours and satiety ratings between the group of normal-weight subjects and the group of overweight subjects were analysed with paired Student's $t$ tests. The paired Student's $t$ test was chosen because subjects were individually matched on sex, age and restraint score. Correlation analyses on eating behaviour were performed by means of Pearson's correlation analysis.

The cumulative food intake was fitted per person per product to a quadratic equation: $y=a+b t+c t^{2}$, where $b$ is the constant slope of the curve over time, i.e. initial eating rate, and $c$ is the change in the slope of the curve over time, i.e. rate of deceleration ${ }^{(30,31)}$. Differences in initial eating rate and deceleration rate between the normal-weight and overweight groups were analysed by means of a paired Student's $t$ test.

Rank scores were calculated for all retro-nasal aroma release parameters ( $T_{\max }, I_{\max }$ and AUC) for each test product, since the two food products had a different magnitude of the characteristic retro-nasal aroma release parameters, and the data were not normally distributed. Furthermore, a combined sum rank of rank $I_{\max }$ and rank AUC was calculated per product. This combined ranking is a value with respect to retronasal aroma release intensity and will hereafter be referred to as 'intensity'. Also, a combined sum rank of rank $I_{\max }$ and rank $T_{\max }$ was calculated per product. This combined ranking is a value with respect to retro-nasal aroma release morphology and will hereafter be referred to as 'morphology'(16).

The different characteristic retro-nasal aroma release parameters were compared between the group of normalweight and overweight subjects by means of the Wilcoxon signed rank sum test. Furthermore, retro-nasal release parameters were correlated with BMI and eating behaviours (values obtained from the sensory sessions) by means of Spearman's correlation analysis.

\section{Results}

\section{Eating behaviour and weight status}

Table 2 gives an overview of the mean results on eating behaviour for both normal-weight and overweight subjects and for both test products. There were no statistically significant differences in ad libitum intake, meal duration, eating rate or number of bites between the normal-weight and overweight groups for either test product. The eating rate of the apple pie yogurt in the overweight group was, on average, higher compared with that of the normal-weight group, but this was not significant. The same applies to the mean bite size of the apple pie yogurt, which also tended to be higher in the overweight group. There was a significant difference in mean bite size for spiced rice; the overweight subjects consumed this product, on average, with larger bite sizes than the normal-weight subjects $(t(26)=-2 \cdot 26, P=0 \cdot 03)$.

Ad libitum intake and eating rate were significantly higher $(P<0.05)$ in men compared with those in women, for both test products. Mean bite size and meal duration were also significantly higher $(P<0.05)$ in men, but only for the apple pie yogurt (data not shown).

Initial eating rate and deceleration rate were not significantly different between the normal-weight and overweight groups for either test product. Initial eating rate for the spiced rice was $0.50(\mathrm{SD} 0.65) \mathrm{g} / \mathrm{s}$ (converted $30(\mathrm{SD} \mathrm{39}) \mathrm{g} / \mathrm{min}$ ) for the normal-weight group and $0.58(\mathrm{SD} 0.21) \mathrm{g} / \mathrm{s}$ (converted 35 (SD 13) $\mathrm{g} / \mathrm{min}$ ) for the overweight group. Initial eating rate for the apple pie yogurt was somewhat higher in the overweight group, 2.11 (SD 1.52) g/s (converted 127 (SD 91) g/ $\mathrm{min}$ ), $v$. the normal-weight group, 1.51 (SD 1.19) g/s (converted 91 (SD 71) $\mathrm{g} / \mathrm{min})$, but this was not significant $(t(26)=-1 \cdot 68, P=0 \cdot 10)$.

BMI had no significant correlation $(P>0.05)$ with ad libitum intake or any other eating behaviour (correlation coefficients varied from -0.09 to $0 \cdot 21$ ).

Many of the eating behaviours were significantly correlated $(P<0 \cdot 05)$ with each other (Table 3$)$.

\section{Satiety ratings}

All satiety ratings decreased significantly after ad libitum intake for both products $(P<0.05)$, except for fullness, which, as expected, increased significantly after intake $(P<0 \cdot 05)$. There were no significant differences in satiety ratings between the normal-weight and overweight groups for both products. Thirst was significantly $(t(26)=-3.68$, $P=0.001)$ lower after intake of the apple pie yogurt in the normal-weight group (36 (SD 25)) compared with the overweight group (58 (SD 24)). Table 4 gives an overview of the satiety and thirst ratings per product, averaged over all subjects. 
Table 2. Ad libitum intake, meal duration, eating rate, number of bites and bite size of the normal-weight and overweight subjects for the test products spiced rice and apple pie yogurt

(Mean values and standard deviations)

\begin{tabular}{|c|c|c|c|c|c|c|c|c|}
\hline & \multicolumn{4}{|c|}{ Spiced rice } & \multicolumn{4}{|c|}{ Apple pie yogurt } \\
\hline & \multicolumn{2}{|c|}{$\begin{array}{l}\text { Normal weight } \\
\quad(n 27)\end{array}$} & \multicolumn{2}{|c|}{$\begin{array}{l}\text { Overweight } \\
(n 27)\end{array}$} & \multicolumn{2}{|c|}{$\begin{array}{l}\text { Normal weight } \\
\quad(n 27)\end{array}$} & \multicolumn{2}{|c|}{$\begin{array}{l}\text { Overweight } \\
\quad(n 27)\end{array}$} \\
\hline & Mean & SD & Mean & SD & Mean & SD & Mean & SD \\
\hline Ad libitum intake $(\mathrm{g})$ & 281 & 148 & 276 & 124 & 458 & 216 & 480 & 201 \\
\hline Meal duration (s) & 457 & 189 & 456 & 151 & 315 & 105 & 306 & 106 \\
\hline Eating rate $(\mathrm{g} / \mathrm{min})$ & 37 & 10 & 38 & 15 & 89 & 32 & 100 & 43 \\
\hline Number of bites & 34 & 21 & 28 & 13 & 36 & 17 & 33 & 12 \\
\hline Bite size $(\mathrm{g})$ & 8.7 & $2 \cdot 1$ & $10 \cdot 3^{*}$ & 3.2 & 13.6 & 4.5 & $16 \cdot 2$ & 7.4 \\
\hline
\end{tabular}

${ }^{*}$ Mean value was significantly different from that of the normal-weight group, $t(26)=-2 \cdot 26, P=0.03$.

\section{Retro-nasal aroma release and weight status}

The parameters of retro-nasal aroma release, rank $I_{\max }$, rank AUC and rank $T_{\max }$, were not significantly different between the normal-weight and overweight groups for either test product. Also, the combined ranking for intensity and morphology was not statistically significantly different between the two groups for either test product.

BMI was not correlated with the ranks of $T_{\max }$, AUC and $I_{\max }$ for either test product, nor to the sum ranks for intensity or morphology (correlation coefficients varied between -0.24 and $0 \cdot 11$ ).

\section{Retro-nasal aroma release and eating behaviours}

None of the retro-nasal aroma release parameters (rank $T_{\max }$, rank AUC and rank $I_{\max }$ ) nor the sum ranks for intensity or morphology were significantly correlated with ad libitum intake, meal duration, eating rate, number of bites or mean bite size for either test product (correlation coefficients varied between $-0 \cdot 19$ and $0 \cdot 24$ ).

\section{Eating behaviour and retro-nasal aroma release within an} individual

Subjects showed consistent eating behaviour for both products; ad libitum intake and the other eating behaviours of the spiced rice were strongly correlated with the intake and eating behaviours of the apple pie yogurt. The correlation coefficients were as follows: ad libitum intake $r 0 \cdot 70$, eating rate $r 0.66$, meal duration $r 0.64$, number of bites $r 0.52$ and bite size $r 0.69$ (all $P<0.0001$ ).

Within subjects, rank numbers of $T_{\max }$ and AUC for the spiced rice were significantly correlated with the rank numbers of $T_{\max }$ and AUC for the apple pie yogurt ( $r$ 0.29, $P=0.049$ and $r 0.54, P<0.0001$, respectively). Also, the sum ranks for intensity and morphology for the spiced rice were significantly correlated with that for the apple pie yogurt (intensity $r 0.39, P=0.006$; morphology $r 0.44, P=0.002)$. Only the ranks of $I_{\max }$ were not significantly correlated $(r 0.21$, $P=0 \cdot 15)$ between the spiced rice and apple pie yogurt.

\section{Discussion}

The aim of the present study was to investigate whether eating behaviour or extent of retro-nasal aroma release relates to weight status. Furthermore, we investigated whether differences in eating behaviour, assumed to affect oral sensory exposure, relate to the extent of retro-nasal aroma release. We found a significant difference in the bite size of the spiced rice product between the weight groups; the overweight subjects took on average larger bite sizes than the normal-weight subjects. We found no significant differences between the weight groups in either ad libitum intake, other eating behaviour or extent of retro-nasal aroma release.

Table 3. Correlation coefficients $(r)^{\star}$ between the microstructural eating behaviours $\dagger$

\begin{tabular}{|c|c|c|c|c|c|c|c|c|c|c|}
\hline & \multicolumn{2}{|c|}{$\begin{array}{l}\text { Ad libitum intake } \\
(\mathrm{g})\end{array}$} & \multicolumn{2}{|c|}{$\begin{array}{l}\text { Meal duration } \\
\text { (s) }\end{array}$} & \multicolumn{2}{|c|}{$\begin{array}{l}\text { Eating rate } \\
(\mathrm{g} / \mathrm{min})\end{array}$} & \multicolumn{2}{|c|}{$\begin{array}{c}\text { Number of } \\
\text { bites }\end{array}$} & \multicolumn{2}{|c|}{ Bite size $(\mathrm{g})$} \\
\hline & Rice & Yogurt & Rice & Yogurt & Rice & Yogurt & Rice & Yogurt & Rice & Yogurt \\
\hline Ad libitum intake $(\mathrm{g})$ & - & - & $0 \cdot 71$ & 0.52 & 0.56 & 0.60 & 0.74 & 0.46 & 0.27 & 0.48 \\
\hline Meal duration (s) & 0.71 & 0.52 & - & - & NS & -0.33 & 0.54 & 0.64 & NS & NS \\
\hline Eating rate $(\mathrm{g} / \mathrm{min}) \ddagger$ & 0.56 & 0.60 & NS & -0.33 & - & - & 0.36 & NS & 0.37 & 0.71 \\
\hline Number of bites & 0.74 & 0.46 & 0.54 & 0.64 & 0.36 & NS & - & - & -0.30 & -0.48 \\
\hline Bite size $(\mathrm{g}) \S$ & 0.27 & 0.48 & NS & NS & 0.37 & 0.71 & -0.30 & -0.48 & - & - \\
\hline
\end{tabular}

*Only significant correlations are shown $(P<0.05)$. Some parameters are related since they are based on each other. These correlations are given for information purposes, but a careful interpretation is needed.

† Analyses were performed separately for the spiced rice and the apple pie yogurt $(n 54)$.

¥Eating rate is calculated by dividing total intake by meal duration.

$\S$ Bite size is calculated by dividing total intake by number of bites. 
Table 4. Satiety ratings before and after ad libitum intake of the spiced rice and the apple pie yogurt (Mean values and standard deviations, $n$ 54)

\begin{tabular}{|c|c|c|c|c|c|c|c|c|}
\hline & \multicolumn{4}{|c|}{ Spiced rice } & \multicolumn{4}{|c|}{ Apple pie yogurt } \\
\hline & \multicolumn{2}{|c|}{$\begin{array}{c}\text { Before } \\
\text { ad libitum intake }\end{array}$} & \multicolumn{2}{|c|}{$\begin{array}{c}\text { After } \\
\text { ad libitum intake }\end{array}$} & \multicolumn{2}{|c|}{$\begin{array}{c}\text { Before } \\
\text { ad libitum intake }\end{array}$} & \multicolumn{2}{|c|}{$\begin{array}{c}\text { After } \\
\text { ad libitum intake }\end{array}$} \\
\hline & Mean & SD & Mean & SD & Mean & SD & Mean & SD \\
\hline Hunger & 67 & 21 & 10 & 11 & 68 & 18 & 13 & 12 \\
\hline Fullness & 22 & 17 & 76 & 16 & 23 & 17 & 77 & 19 \\
\hline Desire to eat & 75 & 19 & 21 & 16 & 75 & 16 & 19 & 17 \\
\hline Appetite for something sweet & 56 & 24 & 41 & 29 & 61 & 22 & 12 & 12 \\
\hline Appetite for something savoury & 74 & 21 & 15 & 19 & 71 & 22 & 34 & 27 \\
\hline Prospective consumption & 65 & 16 & 22 & 14 & 65 & 14 & 22 & 18 \\
\hline Thirst & 63 & 21 & 79 & 19 & 57 & 24 & $47^{*}$ & 27 \\
\hline
\end{tabular}

The extent of retro-nasal aroma release was not correlated with eating behaviour such as ad libitum intake and eating rate. The overweight subjects showed comparable eating behaviour with that of normal-weight subjects. Overall, we found that eating behaviour is very consistent within individuals.

Eating behaviour between the weight groups was investigated for two types of test products, i.e. a more neutral spiced rice meal-type product and a highly liked apple pie yogurt. This enabled us to investigate whether possible effects were consistent for two different products. We expected beforehand that differences in eating behaviour would probably be more pronounced in highly liked products. Laessle et $a{ }^{(20)}$ found clear differences in food intake, spoonful size and initial eating rate between normal-weight and obese subjects, using chocolate mousse, which is a highly liked product. Spiegel et al. ${ }^{(32)}$ showed that the mean rate of intake for obese women was higher than that for lean women when the food was of high palatability, and obese women also tended to eat more of the highly palatable food. An earlier study also found that obese subjects ate more high-preference food and less low-preference food than non-obese subjects ${ }^{(33)}$. In contrast to our original expectation, we only found a difference in bite size, and interestingly only for the product type spiced rice and not for the apple pie yogurt.

Eating behaviour in the present study was measured in a laboratory setting. This setting was chosen to be able to measure eating behaviour accurately. A strength of the present study is the combination of using both hidden weighing scales and video observations. Through the video observations, we observed many individual styles of eating, and only with these observations (or life observations) is it possible to count the number of bites accurately. Some people have a tendency to consume several bites from one spoonful, and if one only investigated changes in weighing scale data, then one would draw different conclusions on the number of bites and bite size. Unfortunately, these video observations also have the disadvantage that subjects can feel observed and possibly adapt their eating behaviour to what they expect is socially desirable. To what extent the laboratory setting with video observations influenced the present results is unknown.

Whereas experimental studies have the advantage of being able to measure behaviour very accurately, they do have the disadvantage of having lower external validity. So far, most studies have been performed in laboratory settings, but an interesting study in a real-life setting is the study of Llewellyn et $a l{ }^{(34)}$. They observed the eating rate of 254 twin children at home. They found a significant association between eating rate (bites/min) and adiposity. Studies on adults in real-life settings are much older, and the methods used were not very accurate. For instance, weight status, bite size and food intake were estimated by an observer without any weighing scale or predefined bites ${ }^{(35-38)}$. More studies in real life might be necessary to investigate whether and how obese and overweight subjects differ in eating behaviour from normal-weight subjects.

The characteristics of the study population and the number of subjects are important factors influencing the results. A strength of the present study was the fact that overweight subjects were individually matched with normal-weight subjects based on sex, age and dietary restraint score. We included subjects who were currently not on a diet. Unfortunately, we have no information on their diet history. It is possible that subjects were currently not on a diet but have been on many diets before, which may have affected their current eating behaviour. Additionally, weight-stable subjects were included, but if an overweight subject is truly weight stable, this could mean that he/she is comparable with a normalweight subject in eating behaviour, as also suggested by others ${ }^{(39)}$. Although many methodological challenges go together with investigating dieting, non-weight-stable overweight subjects, this might be the most interesting group to investigate.

For a study investigating retro-nasal aroma release, the present study was relatively large, but where eating behaviour is concerned, the present study was relatively small, and the power to detect relevant differences in the eating rate and ad libitum intake may have been too low. The variation was larger than expected, and sample size calculations using the 
observed variation showed that we needed several dozens of subjects per weight group to find differences in eating rate of $>10 \%$ between groups and several hundreds of subjects per weight group to find differences in the ad libitum intake of $>10 \%{ }^{(40)}$. Of course not all of these subjects would have to be included, because the variation within groups will decrease as groups will become more homogeneous; nevertheless, this raises the question whether relevant differences in ad libitum intake or eating rate can be found with these numbers of subjects. Nonetheless, cross-sectional studies investigating several hundreds to thousands of subjects have shown positive relationships between BMI and self-reported eating rate. In these studies, eating quickly was associated with overweight $^{(41-43)}$ and reporting to eat faster was an independent predictor of weight change ${ }^{(44)}$. However, no conclusions on a causal relationship can be drawn from these cross-sectional studies. Although the existence of an obese eating style is a concept widely assumed to be present, data from the literature on experimental studies are ambiguous. Some studies have found differences in eating behaviours such as intake, eating rate, bite sizes or meal duration between normal-weight and overweight subjects $^{(17-20)}$, whereas others did not ${ }^{(10,45,46)}$. It is possible that differences in eating behaviour might be very subtle, and that we need much larger studies, preferably in real-life settings, to find systematic and consistent differences.

A second aim of the present study was to relate the extent of retro-nasal aroma release to eating behaviour and weight status. Eating faster and taking larger bites most probably lead to shorter oral transit times, and we expect this to lead to lower oral sensory exposure of products ${ }^{(5,6,47)}$. Furthermore, we expected that these types of behaviour would be more present in the overweight group of subjects. A recent study of Ruijschop et al. ${ }^{(16)}$ has shown that ad libitum intake might correlate with retro-nasal aroma release. If retro-nasal aroma release represents (part of) oral sensory exposure, then based on our expectations, this would be correlated with behaviour such as eating rate.

We found no differences in retro-nasal aroma release between the weight groups, which is probably explained by the fact that we also found no clear differences in eating behaviour between the groups. We did observe that eating behaviour differed largely between subjects, for instance in eating rate. Some subjects ate reasonably slowly, whereas others ate reasonably fast. Therefore, aside from weight status, we expected that eating behaviour and, especially, eating rate would be correlated with retro-nasal aroma release parameters. One explanation for not finding this could be that we used fixed spoonfuls of the test product to measure retronasal aroma release. This approach of fixed spoonfuls was a good starting point and probably sufficient to detect differences between persons based on factors such as nasal anatomy, breathing or saliva flow, which are shown to affect aroma release measurements ${ }^{(27)}$. However, this consumption of a standardised spoonful, which was not based on individuals' normal bite size, might not be sufficient enough to relate eating behaviour such as eating rate and bite size to aroma release during an entire meal. Another explanation could be related to the combination of the physical state of the test products and the fixed bite size. Studies have shown that there is a relationship between retro-nasal aroma release and chewing behaviour ${ }^{(15,48)}$. Our products could be relatively easily consumed and did not require extensive oral processing such as chewing, before they could be swallowed. This could have resulted in too little variation in eating behaviour between subjects during consumption of fixed bite sizes. Therefore, a suggestion for further research would be to measure retro-nasal aroma release in a large group of subjects while consuming test foods which require a relatively long oral processing time, at subjects' own preferred eating rate and sizes of bites.

We found no differences in eating behaviour between the weight groups; however, we did observe differences between the test products. Interestingly, the ad libitum intake of the apple pie yogurt was significantly higher compared with the spiced rice. On average, the apple pie yogurt also received higher liking ratings, was eaten significantly faster, with larger bite sizes, and in a shorter period of time. Satiety ratings after intake of both products were quite similar while in grams and joules, subjects consumed significantly more of the yogurt. Although this is speculative, it is possible that subjects passively overconsumed from the yogurt, and that this has to do with the manner of eating. Within products, eating behaviours such as eating rate and bite size were correlated with ad libitum intake. However, it is important to note here that a careful interpretation of these correlations is necessary since some of the behaviours are partly calculated from each other in the present study. Nevertheless, this correlation between eating rate and bite size with ad libitum intake has also been shown in our previous studies ${ }^{(6,9)}$. Other studies have shown that eating faster and eating with larger bite sizes lead to a higher food intake ${ }^{(2-4,49,50)}$.

Instead of trying to find an obese eating style as a group behaviour, we should focus more on individual behaviour. Subjects showed consistent eating behaviour for both test products. Subjects who consumed a large amount of one product also consumed a large amount of the other product. The same holds for the other eating behaviours. Since eating rate and bite size have been shown to affect food intake, it seems important to further investigate whether decreasing someone's eating rate, bite size or other important parameter would be an effective strategy to decrease food intake and not focus or quantify the level it is now. This seems to have an effect as shown, for instance, by the study of Walden et $a l^{(49)}$, Andrade et $a l^{(3)}$ and also by our own previous study ${ }^{(6)}$, but more longer-term studies in real life and non-laboratory settings are necessary.

In conclusion, the present study showed no clear differences in eating behaviour or retro-nasal aroma release between the normal-weight and overweight subjects and no correlation between eating behaviour and the extent of retro-nasal aroma release. Both eating behaviour and retro-nasal aroma release seem to be subject specific. Eating behaviour might be a characteristic of an individual but not by definition a characteristic for a group of people based on their weight. The present study was one of the first studies to relate 
eating behaviour to retro-nasal aroma release, and more research under non-standardised eating conditions is necessary to investigate whether extent of retro-nasal aroma release can be used as a marker for (part of) oral sensory exposure.

\section{Acknowledgements}

We thank all subjects for participating in the present study. Furthermore, we would like to thank Natasja Hück for her practical assistance, Annereinou Dijkstra and Jan van Riel for performing the retro-nasal aroma release measurements and Tineke van Roekel for performing the chemical analysis of the test products. The authors' responsibilities were as follows: N. Z. designed the study, collected and analysed the data and wrote the manuscript. A. J. B. helped in designing the study, collected the data and contributed to the manuscript. M. M., A. S., R. M. A. J. R. and C. d. G. helped in designing the study, and provided significant advice and consultation and contributed to the manuscript. There are no conflicts of interest to declare. The present study was funded by the Top Institute Food and Nutrition.

\section{References}

1. World Health Organization (2000) Obesity: preventing and managing the global epidemic. Report of a WHO consultation. World Health Organ Tech Rep Ser 894, 1-253.

2. Martin CK, Anton SD, Walden H, et al. (2007) Slower eating rate reduces the food intake of men, but not women: implications for behavioral weight control. Behav Res Ther $\mathbf{4 5}$, 2349-2359.

3. Andrade AM, Greene GW \& Melanson KJ (2008) Eating slowly led to decreases in energy intake within meals in healthy women. J Am Diet Assoc 108, 1186-1191.

4. Kissileff HR, Zimmerli EJ, Torres MI, et al. (2008) Effect of eating rate on binge size in bulimia nervosa. Physiol Behav 93, 481-485.

5. Zijlstra N, Mars M, de Wijk RA, et al. (2008) The effect of viscosity on ad libitum food intake. Int J Obes 32, 676-683.

6. Zijlstra N, de Wijk RA, Mars M, et al. (2009) Effect of bite size and oral processing time of a semisolid food on satiation. Am J Clin Nutr 90, 269-275.

7. Viskaal-van Dongen M, Kok FJ \& de Graaf C (2011) Eating rate of commonly consumed foods promotes food and energy intake, Appetite 56, 25-31.

8. de Wijk RA, Zijlstra N, Mars M, et al. (2008) The effects of food viscosity on bite size, bite effort and food intake. Physiol Behav 95, 527-532.

9. Zijlstra N, Mars M, Stafleu A, et al. (2010) The effect of texture differences on satiation in 3 pairs of solid foods. Appetite 55, 490-497.

10. Spiegel TA, Kaplan JM, Tomassini A, et al. (1993) Bite size, ingestion rate, and meal size in lean and obese women. Appetite 21, 131-145.

11. Westerterp KR, Nicolson NA, Boots JM, et al. (1988) Obesity, restrained eating and the cumulative intake curve. Appetite 11, 119-128.

12. Taylor AJ, Linforth RST, Harvey BA, et al. (2000) Atmospheric pressure chemical ionisation mass spectrometry for in vivo analysis of volatile flavour release. Food Chem 71, 327-338.

13. Weel KGC, Boelrijk AEM, Burger JJ, et al. (2003) A protocol for measurement of in vivo aroma release from beverages. J Food Sci 68, 1123-1128.
14. Buettner A, Beer A, Hannig C, et al. (2001) Observation of the swallowing process by application of videofluoroscopy and real-time magnetic resonance imaging - consequences for retronasal aroma stimulation. Chem Senses 26, 1211-1219.

15. Blissett A, Hort J \& Taylor AJ (2006) Influence of chewing and swallowing behavior on volatile release in two confectionery systems. J Texture Studies 37, 476-496.

16. Ruijschop RM, Burgering MJ, Jacobs MA, et al. (2009) Retronasal aroma release depends on both subject and product differences: a link to food intake regulation? Chem Senses 34, 395-403.

17. Hill SW \& McCutcheon NB (1984) Contributions of obesity, gender, hunger, food preference, and body size to bite size, bite speed, and rate of eating. Appetite 5, 73-83.

18. Barkeling B, Rossner S \& Sjoberg A (1995) Methodological studies on single meal food intake characteristics in normal weight and obese men and women. Int J Obes Relat Metab Disord 19, 284-290.

19. Spiegel TA (2000) Rate of intake, bites, and chews - the interpretation of lean-obese differences. Neurosci Biobehav Rev 24, 229-237.

20. Laessle RG, Lehrke S \& Duckers S (2007) Laboratory eating behavior in obesity. Appetite 49, 399-404.

21. Van Strien T (2005) Nederlandse Vragenlijst voor Eetgedrag (NVE). Handleiding (Dutch Eating Behaviour Questionnaire. Manual). Amsterdam: Boom Test Publishers.

22. Hambleton LG \& Noel RJ (1975) Protein analysis of feed, using a block digestion. J AOAC 58, 143-145.

23. William H (1975) Official Methods of Analysis of the Association of Official Analytical Chemists, 12th ed. Washington, DC: Association of Official Chemists, number 14.019, p. 225.

24. Prosky L, Asp NG, Furda J, et al. (1984) Determination of total dietary fiber in foods products and total diets: inter laboratory study. J AOAC 67, 1044-1052.

25. Finlayson G, King N \& Blundell JE (2007) Is it possible to dissociate 'liking' and 'wanting' for foods in humans? A novel experimental procedure. Physiol Behav 90, 36-42.

26. Finlayson G, King N \& Blundell J (2008) The role of implicit wanting in relation to explicit liking and wanting for food: implications for appetite control. Appetite 50, 120-127.

27. Taylor AJ \& Linforth RST (1996) Flavour release in the mouth. Trends Food Sci Technol 7, 444-448.

28. Weel KG, Boelrijk AE, Burger JJ, et al. (2004) New device to simulate swallowing and in vivo aroma release in the throat from liquid and semiliquid food systems. J Agric Food Chem 52, 6564-6571.

29. Weel KG, Boelrijk AE, Alting AC, et al. (2002) Flavor release and perception of flavored whey protein gels: perception is determined by texture rather than by release. I Agric Food Chem 50, 5149-5155.

30. Kissileff HR, Thornton J \& Becker E (1982) A quadratic equation adequately describes the cumulative food intake curve in man. Appetite 3, 255-272.

31. Dovey TM, Clark-Carter D, Boyland EJ, et al. (2009) A guide to analysing universal eating monitor data: assessing the impact of different analysis techniques. Physiol Behav $\mathbf{9 6}$ 78-84.

32. Spiegel TA, Shrager EE \& Stellar E (1989) Responses of lean and obese subjects to preloads, deprivation, and palatability. Appetite 13, 45-69.

33. Hill SW \& McCutcheon NB (1975) Eating responses of obese and nonobese humans during dinner meals. Psychosom Med 37, 395-401. 
34. Llewellyn CH, van Jaarsveld CH, Boniface D, et al. (2008) Eating rate is a heritable phenotype related to weight in children. Am J Clin Nutr 88, 1560-1566.

35. Gaul DJ, Craighead WE \& Mahoney MJ (1975) Relationship between eating rates and obesity. J Consult Clin Psychol 43, 123-125.

36. Dodd DK, Birky HJ \& Stalling RB (1976) Eating behavior of obese and normal-weight females in a natural setting. Addict Behav 1, 321-325.

37. LeBow MD, Goldberg PS \& Collins A (1977) Eating behavior of overweight and nonoverweight persons in the natural environment. J Consult Clin Psychol 45, 1204-1205.

38. Marston $\mathrm{AR}$, London $\mathrm{P}$, Cohen $\mathrm{N}$, et al. (1977) In vivo observation of the eating behavior of obese and nonobese subjects. J Consult Clin Psychol 45, 335-336.

39. Mattes RD \& Campbell WW (2009) Effects of food form and timing of ingestion on appetite and energy intake in lean young adults and in young adults with obesity. I Am Diet Assoc 109, 430-437.

40. Blundell J, De Graaf C, Hulshof T, et al. (2010) Appetite control: methodological aspects of the evaluation of foods. Obes Rev 11, 251-270.

41. Sasaki S, Katagiri A, Tsuji T, et al. (2003) Self-reported rate of eating correlates with body mass index in 18-y-old Japanese women. Int J Obes Relat Metab Disord 27, 1405-1410.

42. Otsuka R, Tamakoshi K, Yatsuya H, et al. (2006) Eating fast leads to obesity: findings based on self-administered questionnaires among middle-aged Japanese men and women. J Epidemiol 16, 117-124.

43. Maruyama K, Sato S, Ohira T, et al. (2008) The joint impact on being overweight of self reported behaviours of eating quickly and eating until full: cross sectional survey. $B M J$ 337, a2002.

44. Gerace TA \& George VA (1996) Predictors of weight increases over 7 years in fire fighters and paramedics. Prev Med 25, 593-600.

45. Westerterp-Plantenga MS, Westerterp KR, Nicolson NA, et al. (1990) The shape of the cumulative food intake curve in humans, during basic and manipulated meals. Physiol Behav 47, 569-576.

46. Westerterp-Plantenga MS, Wouters L \& ten Hoor F (1991) Restrained eating, obesity, and cumulative food intake curves during four-course meals. Appetite 16, 149-158.

47. Ruijschop RMAJ, Zijlstra N, Boelrijk AEM, et al. (2011) Effects of bite size and duration of oral processing on retro-nasal aroma release - features contributing to meal termination. Br J Nutr 105, 307-315.

48. Tarrega A, Yven C, Semon E, et al. (2008) Aroma release and chewing activity during eating different model cheeses. Int Dairy J 18, 849-857.

49. Walden HM, Martin CK, Ortego LE, et al. (2004) A new dental approach for reducing food intake. Obes Res 12, 1773-1780.

50. Weijzen PL, Smeets PA \& de Graaf C (2009) Sip size of orangeade: effects on intake and sensory-specific satiation. Br J Nutr 102, 1091-1097. 